\title{
INOX: Soldagem
}

\section{Aplicação da norma ASTM A923-Prática A para identificação de fases intermetálicas em junta soldada de aço inoxidável superduplex UNS 32750}

\section{ASTM A923-Practice A application to identify intermetallic phases in a UNS S32750 superduplex welded joint}

\section{Sérgio Duarte Brandi \\ Escola Politécnica da USP Engenharia Metalúrgica e de Materiais E-mail: sebrandi@usp.br}

\section{Lauro M.Y. Silveira \\ Prysmian Energia Cabos e Sistemas do Brasil S.A. \\ E-mail: lauro.silveira@prysmian.com}

\section{Daniel L.B. Vasconcellos \\ Prysmian Energia Cabos e Sistemas do Brasil S.A. \\ E-mail: daniel.vasconcellos@prysmian.com}

\section{Resumo}

Os aços inoxidáveis duplex e superduplex apresentam propriedades superiores aos aços inoxidáveis convencionais. Essa superioridade é baseada na composição química e em uma microestrutura balanceada (aproximadamente 50\% de ferrita). Durante a soldagem podem ocorrer alterações, tanto na composição química, como na fração volumétrica das fases presentes, que podem gerar a presença de fases intermetálicas, que alteram as propriedades originais desses aços. O objetivo deste trabalho é de aplicar a norma ASTM A923-Prática A para verificar a presença de fases intermetálicas na junta soldada de aço inoxidável superduplex UNS 32750. Foram soldados tubos de UNS 32750 com diâmetros externos de 18 e $44 \mathrm{~mm}$ e espessura de $1,5 \mathrm{~mm}$. O processo utilizado foi o TIG orbital, com adição de $25 \mathrm{Cr}-10 \mathrm{Ni}-4 \mathrm{Mo}$ e diâmetro de $0,8 \mathrm{~mm}$. O metal de base e as juntas soldadas foram caracterizados tanto em microscopia óptica como em microscopia eletrônica de varredura. Os resultados mostraram que não houve a precipitação de fases intermetálicas detectadas pela norma ASTM A923, porém na ZAC dos dois tubos estudados apareceram pequenas regiões com precipitação de nitretos de cromo, que também podem alterar as propriedades das juntas soldadas.

Palavras chaves: Aço inoxidável superduplex, soldagem TIG, fases intermetálicas.

\section{Abstract}

Duplex and superduplex stainless steels present superior mechanical and corrosion properties when compared to usual stainless steels. This superiority is based on chemical composition when in a balanced microstructure (approximately $50 \%$ of ferrite). During welding, changes may occur in both, the chemical composition and volume fraction of phases in the material, which may generate the presence of intermetallic phases and, as a consequence, modify the mechanical and corrosion properties of this group of stainless steels. The objective of this work is to apply ASTM A923- Practice A to verify the presence of intermetallic phases in welded joints of UNS 32750 su-perduplex stainless steel. Tubes of UNS 32750, with external diameters of 18 and $44 \mathrm{~mm}$ and a thickness of $1.5 \mathrm{~mm}$, were welded using orbital GTAW, with filler metal 25Cr-10Ni-4Mo and a diameter of $0.8 \mathrm{~mm}$. The metal-based and welded joints were characterized by optical and scanning electron microscopy. The results showed that there was no precipitation 
Aplicação da norma ASTM A923-Prática A para identificação de fases intermetálicas em junta soldada de ...

\begin{abstract}
of the intermetallic phase, such as sigma phase, detected by ASTM A923, but the HAZ of the two tubes studied presented small regions with chromium nitrides, which can also change the properties of welded joins.
\end{abstract}

Keywords: Superduplex stainless steel, GTAW process, intermetallic phases.

\section{Introdução}

Os aços inoxidáveis duplex e superduplex são ligas Fe-Cr-Ni-Mo que possuem o nitrogênio como elemento de liga, substituindo parcialmente o níquel, com o objetivo de melhorar tanto as propriedades mecânicas como as de corrosão além de diminuir o custo destes materiais [Solomon (1982), Nilsson (1992), Charles (1991)]. Eles possuem diversas aplicações industriais como na prospecção de petróleo, química, petroquímica e papel e celulose, entre outras. As propriedades superiores dos aços inoxidáveis duplex são obtidas através da composição química e de um tratamento termomecânico durante a conformação mecânica a aproximadamente $1200^{\circ} \mathrm{C}$ [Solomon (1982), Novak (1977)], originando uma microestrutura balanceada, composta de, aproximadamente, 50\% de ferrita e $50 \%$ de austenita. Qualquer alteração posterior nessas frações volumétricas, causadas pelo processamento do material, pode reduzir muito as propriedades desses aços.

As transformações de fase, no estado sólido, mais relevantes, nos aços inoxidáveis duplex e superduplex são: carbonetos de cromo $\mathrm{M}_{23} \mathrm{C}_{6}$.Weiss et al. (1972)], fase sigma $(\sigma)$ [Brandi (92), Southwick et al. (1980)], $\alpha^{6}$ (fragilização de $475^{\circ} \mathrm{C}$ ) [Solomon et al. (1979), Brandi et al. (1992)], nitreto de cromo (CrN) [Hertzman (1986), Ramirez (2003)] e austenita secundária [Brandi (1995), Lippold (1994)]. Todas essas fases apresentam um caráter fragilizante, seja por um aumento de dureza, seja por formação de zonas empobrecidas em cromo na microestrutura, seja por alteração na composição química original.
A metalurgia da soldagem dos aços inoxidáveis duplex e superduplex deve ser estudada com base nas transformações de fase que ocorrem, tanto na zona fundida (ZF), como na zona afetada pelo calor (ZAC), pois tais transformações afetam a fração volumétrica de austenita, isto é, afetam o balanceamento original da microestrutura do material comorecebido [Brandi (1997), Brandi (2003)].

Para equilibrar a microestrutura da ZF, pode-se utilizar metal de adição com porcentagens de elementos de liga diferentes das do metal base [Folkhard (1988)]. Geralmente utilizam-se metais de adição com 9 a $10 \%$ de Ni para produzir, na zona fundida, uma fração volumétrica de austenita próxima de $50 \%$, qualquer que seja a velocidade de resfriamento da junta [16]. Assim, nessa região da junta soldada, a fração volumétrica da austenita é similar à do metal de base e, fato que minimiza a precipitação de nitretos de cromo na ferrita. Por outro lado, o equilíbrio da microestrutura na ZAC é obtido através do controle da energia de soldagem e da velocidade de resfriamento da junta.

Os objetivos desse trabalho são: avaliar o teor de ferrita da junta soldada; analisar a microestrutura da zona fundida e da zona afetada pelo calor; verificar a presença de fases intermetálicas que podem afetar o desempenho da junta.

\section{Materiais e métodos}

Tubos de aço inoxidável superduplex UNS 32750, sem costura, com diâmetros externos de 18 e $44 \mathrm{~mm}$ e espessura de 1,5 mm foram soldados utilizando-se TIG orbital, com adição de 25Cr-10Ni-4Mo e diâmetro de 0,8 mm. Foram usados os seguintes parâmetros de soldagem: tensão de $12 \mathrm{~V}$, corrente de $80 \mathrm{~A}$, velocidade de soldagem de 1,5 mm/s e vazão de gás argônio de 12 l/min.

Foram feitas medidas do teor de ferrita, tanto nos tubos fornecidos como nas zonas fundidas das juntas soldadas. As medidas foram realizadas empregando-se ferritoscópio marca Fischer, utilizando-se padrão de 10 a
$80 \%$ de ferrita. Foram feitas 5 medidas em cada corpo-de-prova. Os resultados foram corrigidos para as curvaturas dos tubos soldados.

Os corpos-de-prova, compostos de uma amostra do tubo sem soldagem e dois cortes de cordões de solda realizados nos tubos de 18 e 44 mm de diâmetro externo, foram preparados metalograficamente. As amostras foram atacadas eletroliticamente com solução aquosa de ácido oxálico 10\% para evidenciar eventuais presenças de precipitação de carbonetos ou nitretos nos contornos de grão ferrita/ferrita e/ou nas interfaces ferrita/ austenita das zonas fundidas das juntas soldadas. Os mesmos corpos-de-prova, para caracterização metalográfica também foram analisados no microscópio eletrônico de varredura (MEV), quando, então, microrregiões foram realizadas análises químicas semi-quantitativas por dispersão de energia de micro-regiões nas zonas fundidas dos dois tubos, para estimativa do índice de corrosão por pites $\left(\mathrm{IP}_{N}\right)$ e da temperatura crítica de corrosão por pites (CPT).

Para detectar a presença de fases intermetálicas, no aço UNS 32750, foi empregada a norma ASTM A92-01 intitulada "Standard Test Methods for Detecting Detrimental Intermetallic Phase in Wrought Duplex Austenitic/ Ferritic Stainless Steels”, prática A "Sodium hydroxide etch test for classification of etch structures of duplex stainless steels”, que utiliza um ataque eletrolítico, em condições normalizadas, empregando-se uma solução aquosa de $\mathrm{NaOH} 40 \%$.

\section{Resultados e discussão}

\subsection{Medida do teor de ferrita no metal de base na zona fundida}

Os valores de ferrita medidos estão apresentados na Tabela 1, sendo que as correções foram feitas devido às curvaturas dos tubos. O teor de ferrita médio especificado, para o aço superduplex 
Sérgio Duarte Brandi et al.

\begin{tabular}{l|c}
\hline \multicolumn{1}{c|}{ Corpo-de-prova } & Ferrita (\%) \\
\hline Tubo com diâmetro de 18 mm & $47,3 \pm 1,7$ \\
\hline ZF (diâmetro de 18 mm) & $40,1 \pm 3,2$ \\
\hline Tubo com diâmetro de 44 mm & $48,1 \pm 1,2$ \\
\hline ZF (diâmetro de 44 mm) & $46,1 \pm 3,2$ \\
\hline
\end{tabular}

Tabela 1 - Teor de ferrita medido nos tubos de aço UNS 32750 e nas zonas fundidas (ZF) dos cordões de solda.

UNS 32750, é de, aproximadamente, $50 \%$, calculado pelo diagrama WRC92. Da mesma maneira, a especificação do metal de solda sem diluição ficam em torno de $50 \%$ de ferrita. Os valores da Tabela 1 mostram que os valores de ferrita para os dois tubos estão dentro do especificado. Já o cordão de solda do tubo de diâmetro de $18 \mathrm{~mm}$ apresenta valores médios de ferrita um pouco menores que os do tubo de $44 \mathrm{~mm}$, embora exista uma superposição de valores, quando se empregam os desvios calculados. Essa pequena diferença poderá significar que existe uma probabilidade maior de ocorrência de nitretos de cromo no tubo de maior diâmetro.

\subsection{Caracterização metalo- gráfica do metal de base e das juntas soldadas}

A Figura 1 apresenta uma microestrutura ferrítica-austenítica, típica de aço superduplex, sem precipitação aparente nos contornos de grão ferrita/ ferrita e austenita/austenita e interfaces ferrita/austenita, caracterizando um material com propriedades dentro das especificadas, como a temperatura crítica para corrosão por pites (CPT), que está ao redor de $80^{\circ} \mathrm{C}$, conforme dados fornecidos pelo fabricante.

As Figuras 2 e 3 apresentam micrografias obtidas com microscópio óptico das juntas soldadas dos dois tubos. Nas micrografias das Figuras 2a e 3a, reveladas pelo ataque com ácido oxálico, nota-se uma alteração na morfologia e no tamanho da ferrita e da austenita. Na ZAC dos dois tubos, aparecem poucas regiões com precipitação de nitretos de cromo na ferrita, como mostra a Figura 2a. Já as zonas fundidas são constituídas de ferrita e austenita primária e secundária. Elas não apresentaram nenhum tipo de precipitação de fases intermetálicas que pudesse afetar o desempenho da junta, como mostrado na Figura 3a. Com isto, a temperatura crítica, para corrosão por pites (CPT) da zona fundida, deve estar ao redor de $50^{\circ} \mathrm{C}$, conforme dados fornecidos pelo fabricante.

Para confirmar esses resultados, os corpos-de-prova foram observados com maior aumento no microscópio eletrônico de varredura. Os resultados das microestruturas observadas estão apresentados nas Figuras 2b e 3b. As análises dessas figuras mostram que não existem fases intermetálicas (CrN) precipitadas nos contornos de grão ferrita/ferrita e nas interfaces ferrita/austenita nos metais de base (Figura 1b). As Figuras 2b e 3b foram retiradas nas zonas afetadas pelo calor das soldas dos dois tubos, mostrando regiões sem a presença de CrN, embora tenham sido observadas regiões como aquelas apresentadas na Figura 2a. A Figura 3b apresenta uma intensa precipitação de aus-
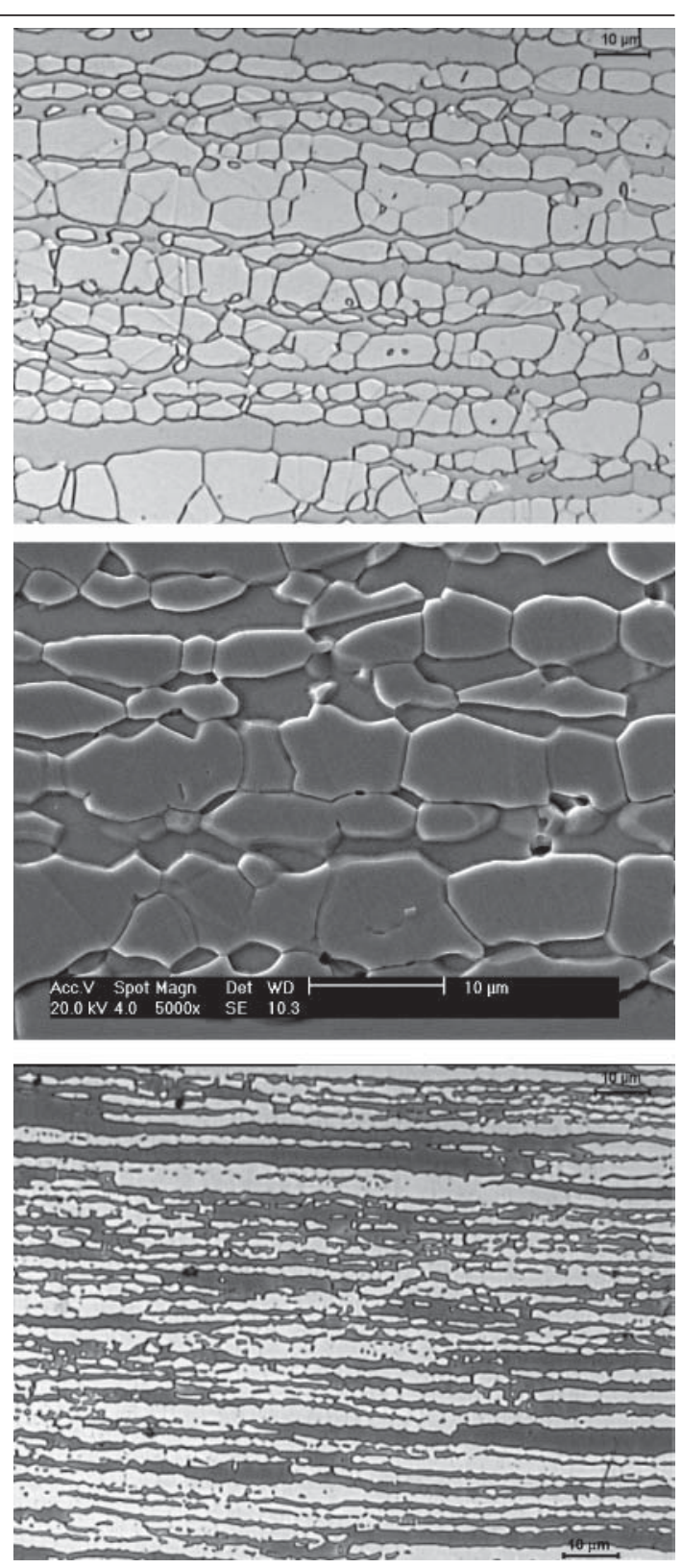

Figura 1 - Micrografias do metal de base dos tubos (UNS 32750). Em (a) microestrutura típica composta de ferrita e austenita. Microscópio óptico. Aumento: 1000X. Ataque: ácido oxálico 10\%; ; em (b) Microscópio eletrônico de varredura. Aumento: 5000X. Ataque: ácido oxálico 10\%; em (c) resultado do emprego da prática A da norma ASTM A923 - 01. Microscópio óptico. Aumento: 500X. Ataque: $\mathrm{NaOH} 40 \%$

tenita secundária no interior do grão ferrítico. Essa fase possui menor quantidade dos elementos de liga presentes. A Tabela 2 apresenta valores de composição química das fases presentes tanto no metal de base como na zona fundida.

Observando-se a Tabela 2, nota-se que existe uma diferença na temperatura crítica de corrosão 

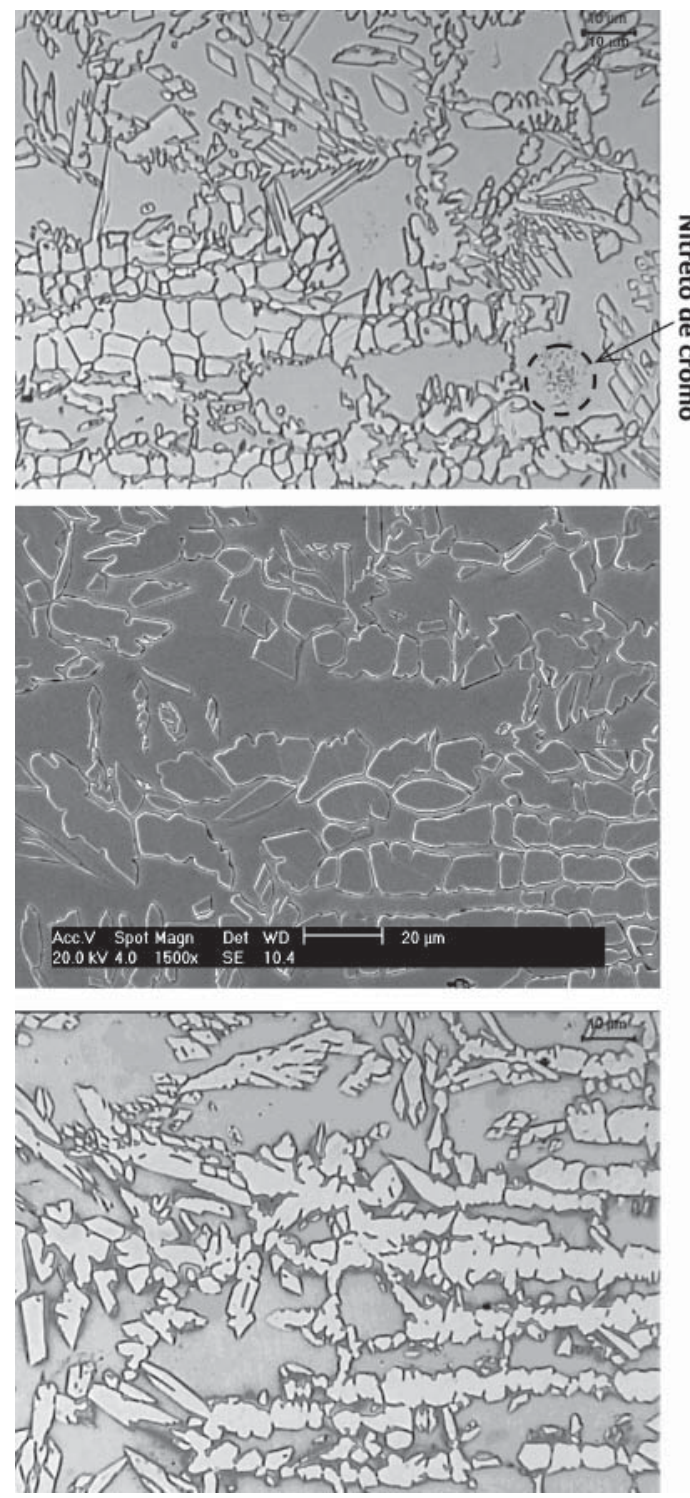

Figura 2 - Micrografias da zona afetada pelo calor da junta soldada dos tubos (UNS 32750). Em (a) microestrutura típica composta de ferrita e austenita. Microscópio óptico. Aumento: 1000X. Ataque: ácido oxálico 10\%.; em (b) Microscópio eletrônico de varredura. Aumento: 5000X. Ataque: ácido oxálico 10\%; em (c) resultado do emprego da prática A da norma ASTM A923 - 01. Microscópio óptico. Aumento: 500X. Ataque: $\mathrm{NaOH} 40 \%$.
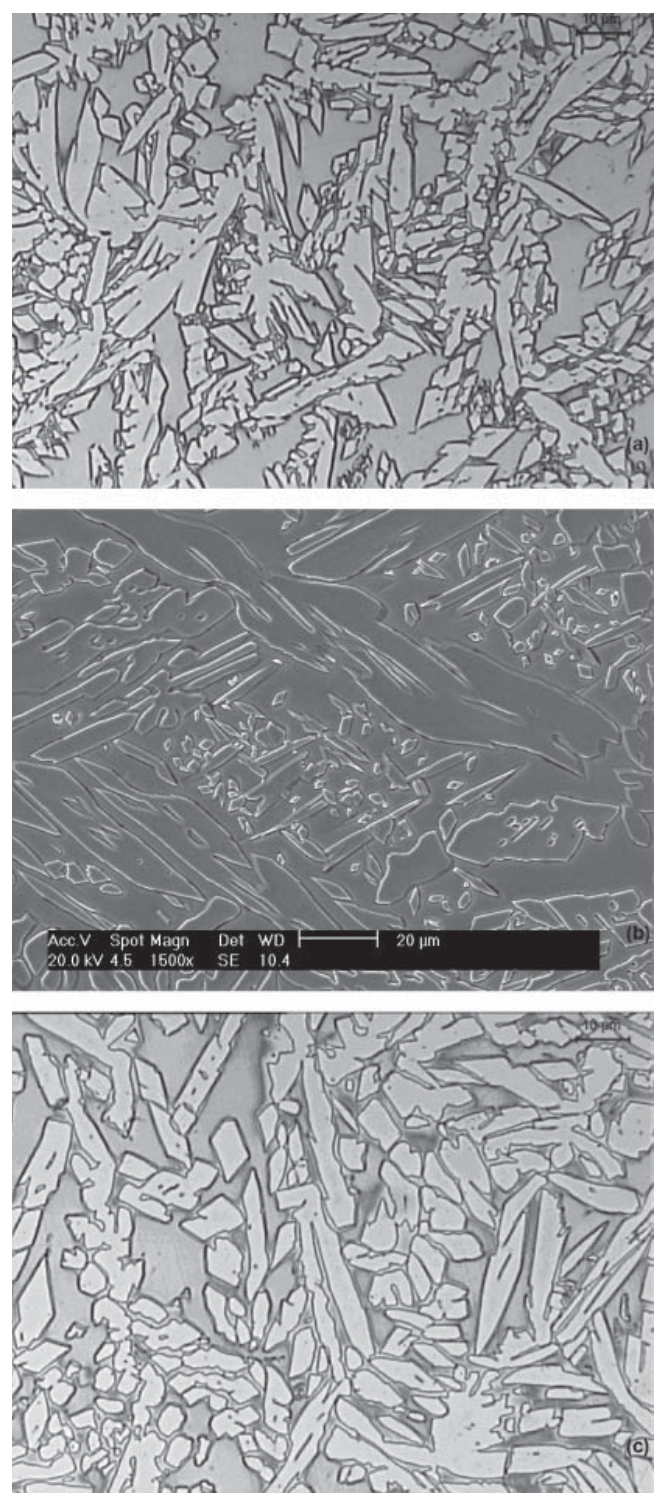

Figura 3 - Micrografias da zona fundida da junta soldada dos tubos (UNS 32750). Em (a) microestrutura típica composta de ferrita e austenita. Microscópio óptico. Aumento: 1000X. Ataque: ácido oxálico 10\%.; em (b) Microscópio eletrônico de varredura. Aumento: 5000X. Ataque: ácido oxálico 10\%; em (c) resultado do emprego da prática A da norma ASTM A923 - 01. Microscópio óptico. Aumento: 500X. Ataque: $\mathrm{NaOH} 40 \%$.

por pites estimada (CPT) nas diferentes regiões analisadas. A austenita tem um CPT menor que a ferrita, por ter teores de Cr e Mo menores que a ferrita, embora tenha uma concentração maior de nitrogênio. De todos os resultados apresentados, a austenita secundária apresenta os menores valores de CPT de todas as fases analisadas $\left(48,8^{\circ} \mathrm{C}\right)$, próximos dos valores publicados na literatura.

\subsection{Ensaio para detectar a presença de fases intermetálicas no metal de base e juntas soldadas de aço inoxidável superduplex UNS 32750.}

Para verificar a existência de fases intermetálicas, no aço UNS 32750, foi empregada a norma ASTM A923-01 prática A. A Figura 1c apresenta os resultados da prática A para os metais de base dos tubos soldados. Os resultados mostraram que 
não foram detectadas a presença de fases intermetálicas nos dois tubos. As Figuras 2c e 3c mostram os resultados para a zona afetada pelo calor e para a zona fundida dos dois tubos. Embora pareça que existem regiões escuras, que, segundo a norma, seriam um indicativo da presença de fases intermetálicas, elas foram geradas por manchas que ocorreram ou durante a secagem das amostras ou devido ao resíduo de ataque que ficou concentrado em algumas regiões, causado pelo relevo da microestrutura. Em uma primeira avaliação, com base nessa prática, não existem indícios de precipitação de fases intermetálicas nas regiões analisadas, embora tenham sido observados nitretos de cromo nas zonas afetadas pelo calor dos dois materiais, conforme observado por outras técnicas de análise.

\section{Conclusões}

Com base nas técnicas empregadas e nos materiais utilizados, é possível concluir que, em um primeiro momento, não existe precipitação de fases intermetálicas em quantidade suficiente para afetar a resistência à corrosão das juntas soldadas com base na norma ASTM 923-01 prática A. Sugere-se que práticas adicionais sejam empregadas para avaliar, com maior segurança, a resistência à corrosão das juntas soldadas fornecidas, uma vez que a presença de nitretos de cromo não são detectados por esta prática.

\section{Agradecimentos}

Os autores gostariam de agradecer ao MCT/FINEP pelo projeto 2882/04, a Prysmian Energia Cabos e Sistemas do Brasil S.A. através do Sr. Carlos Alberto Godinho e ao grupo LIFE\&MO através do Prof. Dr. Celso Pupo Pesce.

Tabela 2 - Composição química por energia dispersiva do metal de base e do cordão de solda com a estimativa do IPN e da $\mathrm{CPT}$, em ${ }^{\circ} \mathrm{C}$.

\begin{tabular}{l|c|c|c|c|c|c|c|c|c}
\hline \multicolumn{4}{c|}{ Metal de Base } & \multicolumn{6}{c}{ Cordão de solda } \\
\cline { 3 - 10 } & \multicolumn{5}{c}{ Zona fundida } \\
\hline Elem. & $\%$ & $\%$ at. & & & Elem. & $\%$ & $\%$ at. & & \\
\hline $\mathrm{Si}$ & 0,64 & 1,28 & & & $\mathrm{Si}$ & 0,66 & 1,3 & & \\
\hline $\mathrm{Mo}$ & 4,25 & 2,47 & & & $\mathrm{Mo}$ & 4,27 & 2,48 & & \\
\hline $\mathrm{Cr}$ & 25,5 & 27,27 & & & $\mathrm{Cr}$ & 25,38 & 27,17 & & \\
\hline $\mathrm{Fe}$ & 62,95 & 62,68 & $\mathrm{IP}_{\mathrm{N}}$ & $\mathrm{CPT}\left({ }^{\circ} \mathrm{C}\right)$ & $\mathrm{Fe}$ & 61,11 & 60,91 & $\mathrm{IP}_{\mathrm{N}}$ & $\mathrm{CPT}\left({ }^{\circ} \mathrm{C}\right)$ \\
\hline $\mathrm{Ni}$ & 6,66 & 6,31 & 43,8 & 60,8 & $\mathrm{Ni}$ & 8,59 & 8,14 & 43,8 & 60,7 \\
\hline
\end{tabular}

Ferrita

\begin{tabular}{c|c|c|c|c|c|c|c|c|c}
\hline Elem. & $\%$ & $\%$ at. & & & Elem. & $\%$ & $\%$ at. & & \\
\hline $\mathrm{Si}$ & 0,62 & 1,23 & & & $\mathrm{Si}$ & 0,59 & 1,18 & & \\
\hline $\mathrm{Mo}$ & 5,1 & 2,96 & & & $\mathrm{Mo}$ & 4,5 & 2,61 & & \\
\hline $\mathrm{Cr}$ & 26,89 & 28,81 & & & $\mathrm{Cr}$ & 25,5 & 27,34 & & \\
\hline $\mathrm{Fe}$ & 62,52 & 62,37 & $\mathrm{IP}_{\mathrm{N}}$ & $\mathrm{CPT}\left({ }^{\circ} \mathrm{C}\right)$ & $\mathrm{Fe}$ & 61,36 & 61,24 & $\mathrm{IP}_{\mathrm{N}}$ & $\mathrm{CPT}\left({ }^{\circ} \mathrm{C}\right)$ \\
\hline $\mathrm{Ni}$ & 4,86 & 4,62 & 44,2 & 61,7 & $\mathrm{Ni}$ & 8,04 & 7,63 & 40,8 & 53,9 \\
\hline
\end{tabular}

\section{Austenita}

\begin{tabular}{|c|c|c|c|c|c|c|c|c|c|}
\hline Elem. & $\%$ & $\%$ at. & & & Elem. & $\%$ & $\%$ at. & & \\
\hline $\mathrm{Si}$ & 0,54 & 1,07 & & & $\mathrm{Si}$ & 0,61 & 1,21 & & \\
\hline Mo & 3,34 & 1,93 & & & Mo & 3,48 & 2,01 & & \\
\hline $\mathrm{Cr}$ & 24,02 & 25,66 & & & $\mathrm{Cr}$ & 25,01 & 26,71 & & \\
\hline $\mathrm{Fe}$ & 63,99 & 63,66 & $\mathrm{IP}_{\mathrm{N}}$ & CPT $\left({ }^{\circ} \mathrm{C}\right)$ & $\mathrm{Fe}$ & 61,71 & 61,37 & $\mathrm{IP}_{\mathrm{N}}$ & CPT $\left({ }^{\circ} \mathrm{C}\right)$ \\
\hline \multirow[t]{8}{*}{$\mathrm{Ni}$} & 8,11 & 7,68 & 38,9 & 49,4 & $\mathrm{Ni}$ & 9,19 & 8,69 & 40,3 & 52,7 \\
\hline & & & & & \multicolumn{5}{|c|}{ Austenita secundária } \\
\hline & & & & & Elem. & $\%$ & $\%$ at. & & \\
\hline & & & & & $\mathrm{Si}$ & 0,59 & 1,16 & & \\
\hline & & & & & Mo & 3,11 & 1,8 & & \\
\hline & & & & & $\mathrm{Cr}$ & 24,52 & 26,16 & & \\
\hline & & & & & $\mathrm{Fe}$ & 62,61 & 62,24 & $\mathrm{IP}_{\mathrm{N}}{ }^{\left({ }^{*}\right)}$ & $\mathrm{CPT}^{(* *)}\left({ }^{\circ} \mathrm{C}\right)$ \\
\hline & & & & & $\mathrm{Ni}$ & 8,5 & 8,04 & 38,6 & 48,8 \\
\hline
\end{tabular}


Aplicação da norma ASTM A923-Prática A para identificação de fases intermetálicas em junta soldada de ...

\section{Referências bibliográficas}

BRANDI, S.D. Estudo da soldabilidade do aço inoxidável duplex DIN W. Nr. 1.4462 (UNS S31803). EPUSP, 1992. 265 p. (Tese de Doutorado).

BRANDI, S.D., PADILHA, A.F. Weldability of duplex stainless steel UNS S31803. In: AMERICAN WELDING SOCIETY ANNUAL MEETING, 73. Anais... Miami - EUA: AWS, march. 22-27, 1992, p. 22-23.

BRANDI, S.D., LIPPOLD, J.C., LIN, W. Effect of preheat temperature on multipass HAZ performance of duplex stainless steels. In: AMERICAN WELDING SOCIETY ANNUAL MEETING, 76. Anais... Cleveland, OH, EUA: AWS, 1995. p.32.

BRANDI, S.D., LIPPOLD, J.C. Considerações sobre a metalurgia da soldagem de aços inoxidáveis duplex e superduplex. Metalurgia e Materiais, v. 53, n. 463, p. 141-146, 1997.

BRANDI, S.D. Some aspects of weldability and jointability of duplex stainless steels. Materials Science Forum, v. 426-432, p. 4063-4068, 2003.

CHARLES, J. Super duplex stainless steels: structure and properties. In: CONFERENCE DUPLEX STAINLESS STEELS'91. Anais... Beaune Bourcogne France, 1991, p. 3-48.

FOLKHARD, E. Welding metallurgy of stainless steels. Austria: Springer-Verlag, 1988, p. 188-190, 278 p.

HERTZMAN, S., ROBERTS, W., LINDENMO, M. Microstructure and properties of nitrogen alloyed duplex stainless steel after welding treatments. In: DUPLEX STAINLESS STEEL 86 INTERNATIONAL CONFERENCE, VAN LIERE, J. (Ed.) Anais... The Hague - Suécia, 26-28 Oct, 1986. p. 257-267.
LIPPOLD, J.C., LIN, W., BRANDI, S.D.,VAROL, I., BAESLACK III, W.A. Heat affected zone microstructure and properties in commercial duplex stainless steels. In: FOURTH INTERNATIONAL CONFERENCE DUPLEX STAINLESS STEELS (Duplex 94). Anais... Glasgow, Escócia, 1994. paper 116.

NILSSON, J.O. Superduplex stainless steels. Materials Science and Technology, v. 8, n. 8, p. 685-700, 1992.

NOVAK, C.J. Structure and constitution of wrought austenitic stainless steel. In:__ Handbook of stainless steel, (Ed.). PECKNER, D. \& BERNSTEIN, I.M. USA: Mc Graw-Hill, 1977. p. 4-1 a 4-78, 687p.

RAMIREZ, A. J., LIPPOLD, J.C., BRANDI, S.D. The relationship between chromium nitride and secondary austenite precipitation in duplex stainless steels. Metallurgical and Materials Transactions, v. 34A, n. 8, p. 1575-1597, 2003.

SOLOMON, H.D., KOCH, E.F. High temperature precipitation of alpha prime in a multicomponent duplex stainless steel. Scripta Metallurgica, v. 13, n. 10, p. 971-974, 1979.

SOLOMON, H.D., DEVINE, T.M. A tale of two phases. In: CONFERENCE DUPLEX STAINLESS STEELS'82 Anais... Ohio EUA: American Society of Metals, 1983. p. 693-756.

SOUTHWICK, P.D., HONEYCOMBE, R.W.K. Decomposition of ferrite to austenite in $26 \% \mathrm{Cr}-5 \% \mathrm{Ni}$ stainless steel. Metal Science, v. 14, n. 7, p.253-261, 1980.

WEISS, B., STICKLER, R. Phase instabilities during high temperature exposure of 316 austenitic stainless steel. Metallurgical Transactions, v. 3A, n. 4, p. 851-866, 1972.

Artigo recebido em 20/08/2009 e aprovado em 18/01/2010.

\section{A REM tem novo endereço:}

\section{FUNDAÇÃO GORCEIX - REM}

Rua Carlos Walter Marinho Campos, 57 Bairro: Vila Itacolomy 35400-000 - Ouro Preto - MG

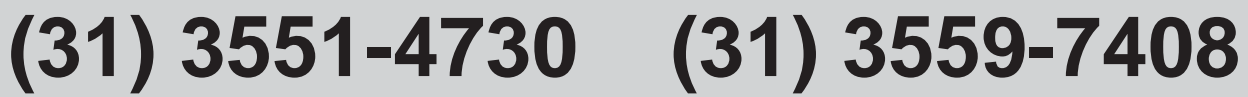

\section{www.rem.com.br}

